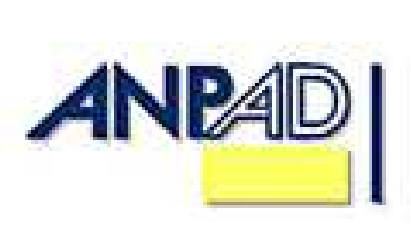

Disponível em

http://www.anpad.org.br/rac

RAC, Rio de Janeiro, v. 16, n. 6, art. 1, pp. 765-783, Nov./Dez. 2012

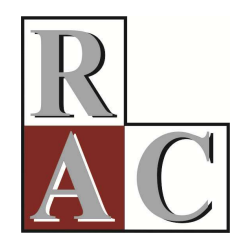

\title{
A Evolução do Ensino da Pós-graduação Estrito Senso em Administração no Brasil
}

\author{
The Evolution of Brazilian Graduate Business Administration Programs
}

\author{
Claudia Brito Silva Cirani * \\ E-mail: cloubrito@hotmail.com \\ Universidade Nove de Julho - PMDA/Uninove \\ São Paulo, SP, Brasil. \\ Heloísa Helena Marques da Silva \\ E-mail: hheloiza@gmail.com \\ Universidade Nove de Julho - PMDA/Uninove \\ São Paulo, SP, Brasil. \\ Milton de Abreu Campanario \\ E-mail: macampanario@uol.com.br \\ Universidade Nove de Julho - PMDA/Uninove \\ São Paulo, SP, Brasil.
}

* Endereço: Claudia Brito Silva Cirani

Avenida Francisco Matarazzo, 612, prédio C, Água Branca, São Paulo/SP, 05001-000. 


\title{
Resumo
}

O objetivo deste trabalho é analisar a evolução do ensino da pós-graduação estrito senso (doutorado, mestrado e mestrado profissional) em Administração no Brasil. Para tanto, foi utilizada a base de dados GeoCAPES da Coordenação de Aperfeiçoamento de Pessoal de Nível Superior (CAPES), que abrange a análise do período de 1998 a 2011, abarcando quatro triênios de avaliação daquela instituição e os dois primeiros anos do último triênio ainda não concluído (2010 e 2011). Com esta série, foi possível analisar indicadores básicos desse nível de ensino, tais como volume e qualidade dos programas, corpo docente e discente (matriculados e titulados), tanto no âmbito nacional como regional. Por ser uma análise exploratória, foram utilizados métodos descritivos para apresentação de dados, trabalhados e demonstrados em figuras e tabelas. As conclusões mostraram uma evolução positiva quantitativa e qualitativa ao longo do período analisado. Embora o ensino da pós-graduação estrito senso em Administração tenha sido ampliado de forma significativa, ainda persiste uma enorme desigualdade na distribuição regional dos programas, com uma concentração nas regiões mais ricas do país e um destaque para o forte crescimento de cursos criados pelo setor privado.

Palavras-chave: administração; pós-graduação; indicadores.

\begin{abstract}
The objective of this study is to analyze the evolution of graduate programs (doctorate, master's and professional master's) in Brazilian business administration. The study utilizes the GeoCAPES database from the Coordenação de Aperfeiçoamento de Pessoal de Nível Superior (CAPES). The information from 1998 to 2011 includes four triennial periods of CAPES graduate program evaluations and the first two years (2010 and 1011) of the current triennial of evaluation. Within this series, it is possible to not only verify the development of the programs, but also to compare basic indicators, such as number of authorized programs, grades, teaching staff, students enrolled and titled at the national and regional levels. As an exploratory study, it uses descriptive statistical analysis presented through tables and figures. The conclusions show a positive quantitative and qualitative development over the fourteen years of the studied indicators. Although master's and PhD programs in business administration have grown over the years, an uneven regional distribution still remains in Brazil, concentrated in the richest regions and with private universities showing strong growth at this level of education.
\end{abstract}

Key words: business administration; graduate programs; indicators. 


\section{Introdução}

Introduzido principalmente por Arrow (1962), Nelson e Phelps (1966), e Merton (1969), e posteriormente por vários outros destacados pesquisadores como Dasrupta e David (1994) e Stephan (1996), que faz uma revisão da literatura sobre o tema, o conhecimento adquiriu status conceitual de bem público. Por isso, foi considerado socialmente indivisível, isto é, a utilidade no uso dele por um indivíduo não afeta negativamente o seu uso por outrem. Também, esses autores demonstram que o custo marginal de um usuário adicional de conhecimento é praticamente nulo, isto é, o estoque de conhecimento não diminui com o seu uso intensivo, mas, pelo contrário, aumenta. Outros fatores de produção, como capital, recursos naturais e trabalho (sem conhecimento) têm utilidade decrescente conforme aumenta o seu uso individual (mantendo os outros fatores constantes), perdendo rendimento marginal.

Sobre esse argumento, pode-se afirmar que a "ampliação qualificada da pós-graduação e a expressiva expansão do número de pós-graduandos altamente capacitados são essenciais para o desenvolvimento científico, cultural, tecnológico e social" (Foray, 2004, p. 93). Embora ainda insuficiente, a experiência brasileira de geração de conhecimento na pós-graduação estrito senso nos últimos anos é uma das realizações relativamente mais bem-sucedidas no conjunto do sistema de ensino existente no país, pois vem formando profissionais em praticamente todos os setores da economia, conforme demonstram os dados da Coordenação de Aperfeiçoamento de Pessoal de Nível Superior (CAPES, 2010).

A pós-graduação ${ }^{(1)}$ brasileira estrito senso tem um início relativamente tardio, com a criação da CAPES em 1951, entidade vinculada ao Ministério da Educação cujo objetivo é executar a política nacional de pós-graduação (Silva \& Carvalho, 2007). A pós-graduação em Administração teve início somente em 1967, com um único mestrado criado pela Fundação Getúlio Vargas do Rio de Janeiro FGV-RJ. Nos anos seguintes, outros cursos foram fundados em São Paulo, Minas Gerais, Rio de Janeiro, Rio Grande do Sul, Santa Catarina, Paraíba, Rio Grande do Norte e Distrito Federal. Ainda nos anos 1970, três cursos de doutorado foram criados: dois no estado de São Paulo e um no Rio de Janeiro (Guimarães, Gomes, Odelius, Zancan, \& Corradi, 2009). Como será visto, sua evolução é evidente, respondendo pela quinta posição em alunos matriculados na pós-graduação brasileira, num universo de 47 áreas de conhecimento (CAPES, n.d.a).

Há, ainda, uma incipiente literatura sobre a evolução da pós-graduação estrito senso no país, à qual este estudo busca se agregar, abordando diferentes tópicos. Santos (2003) aponta as dificuldades do setor educacional de pós-graduação, tendo em vista a dinâmica de crescimento da demanda por pessoal qualificado em todas as áreas de conhecimento. Martins (2000) estudou programas de pósgraduação em Ciência do Solo, constatando sua ampliação significativa nos últimos anos, mas ainda limitado para atender o enorme território nacional, que demanda estudos os mais diversificados. Ceretta, Anjos e Siqueira (2008) e Lyra e Haeffner (2008) analisaram a pós-graduação em Agronomia, identificando o mesmo fenômeno de concentração regional e insuficiência no volume de recursos para uma disciplina que apoia um dos tradicionais motores econômicos do país. Esta praticamente não tem fronteiras regionais, dada a enorme riqueza que tal recurso representa em todo território nacional. Ferraro (2005) trata da preparação do professor sob a ótica da pedagogia, que estaria na base de todo e qualquer esforço nacional para melhorar o ensino médio e a própria graduação em educação. Nessa mesma linha, Kuenzer e Moraes (2005) apontam as carências no ensino da educação e da pedagogia como limitantes da expansão do ensino no país. Steiner (2005) analisa a extrema diversidade de condições institucionais para demarcar a relativamente baixa qualidade da pós-graduação brasileira. Outros estudos trazem contribuições sobre temas como exame de grau (Pezzi \& Steil, 2009), características gerais da pós-graduação em nutrição (Kac, Fialho, \& Santos, 2006) e sistema de avaliação dos cursos (Moreira, 2009).

Entretanto, uma análise da literatura sobre o ensino estrito senso da área de Administração indica um número reduzido de pesquisas realizadas sobre diferentes aspectos relacionados a essa pós- 
graduação. Maccari, Rodrigues, Alessio e Quoniam (2008), por exemplo, realizaram uma pesquisaação no programa de Administração da Universidade de São Paulo (USP), visando demonstrar como o sistema de avaliação CAPES pode ser usado para melhorar seu desempenho. Campanario, Maccari, Silva e Faria (2009) desenvolvem uma modelagem de gestão de projetos para propostas de novos programas na área, mostrando a forma de avaliação e os critérios de entrada. Guimarães, Gomes, Odelius, Zancan e Corradi (2009) elaboram estudo sobre rede de programas de pós-graduação em Administração; constatando que a rede social entre os programas analisados é fraca. Para esses autores, a localização geográfica e as linhas de pesquisa dos cursos são fatores importantes na definição da estrutura dessa rede. Há ainda vários estudos bibliométricos em Administração (Moretti \& Campanario, 2009), que buscam caracterizar o tipo de produção científica que está sendo produzida nessa área.

Este trabalho ${ }^{(2)}$ tem o objetivo de avançar no conhecimento sobre a evolução do ensino de pósgraduação em Administração e responder a seguinte pergunta: quais as diferenças significativas nos indicadores - programas $^{(3)}$, docentes, discentes matriculados e titulados - da pós-graduação estrito senso em Administração, no período de 1998 a 2011, considerando as regiões brasileiras e a caracterização das Instituições de Ensino Superior - IES (pública ou privada)? Naturalmente, esta questão pode perfeitamente obter como resposta uma complexa linha de pesquisa, incorporando vários tópicos como desempenho, retorno sobre investimento, distribuição de notas nos programas, aproveitamento do egresso, perfil da demanda, privatização do ensino, entre outros. O presente estudo está organizado de forma a responder a essa pergunta com escopo mais geral, estipulando como objetivo investigar a evolução do ensino da pós-graduação estrito senso em Administração no Brasil ao longo dos 14 anos. Além disso, pretende comparar indicadores entre as regiões sob as diferentes dimensões contidas na questão de pesquisa.

Ressalta-se a importância deste trabalho uma vez que não existem ainda estudos sobre quanto, onde e quando o ensino da pós-graduação estrito senso ${ }^{(4)}$ vem crescendo ao longo do tempo, tanto no âmbito nacional como regional, por tipo de IES. Nesse sentido, os resultados deste trabalho são importantes subsídios para formulação de políticas públicas, sistema de avaliação dos cursos e estratégias das IESs que visem incorporar necessidades e desafios desse nível de ensino no Brasil e, em particular, em cada região do país.

Este trabalho está dividido em cinco seções, incluindo esta introdução. A segunda seção aprofunda o embasamento teórico que sustenta o estudo. A terceira seção expõe, sucintamente, a metodologia adotada. A quarta seção faz uma análise descritiva dos dados coletados da CAPES. Por fim, a quinta seção traz as principais conclusões.

\section{Educação e Desigualdade Econômica}

A grande maioria dos modelos de crescimento econômico, desenvolvidos a partir das contribuições de Solow (1956), incorpora o conhecimento como uma variável crítica. Este mesmo autor inclui, em seu modelo seminal, o capital como fator determinante para explicar o crescimento econômico agregado dos países. Um de seus seguidores mais próximos incorporou o conhecimento como um fator endógeno ao responsabilizá-lo pela descoberta de novas ideias, tecnologias e inovações (Romer, 1994). Por esta proposição, os países com mais capital humano, ou seja, com nível educacional mais alto, são em média mais ricos. Em revisão extensiva da literatura empírica sobre o tema, Coen e Rens (2008) aponta que não há dúvida de que exista uma forte correlação positiva entre nível educacional de um país e sua renda (produto interno bruto [PIB]). Porém, outra variável econômica tão importante quanto o PIB de um país é a forma como ele é distribuído entre sua população, pois há vários trabalhos empíricos que encontram uma relação positiva entre educação e o grau de desigualdade econômica entre famílias e regiões (Gonçalves \& Guimarães, 2008). 
Nos anos 1960, o pesquisador norte americano Jeffrey Williamson (1965) já indicava a existência de uma relação empírica entre desigualdade regional e renda per capita por meio de uma curva em U invertido. Segundo esse autor, regiões em fase inicial de desenvolvimento econômico atraem pessoas mais bem qualificadas e maiores investimentos públicos, implicando em aumento da desigualdade regional. Porém, a partir de determinado ponto, os mecanismos clássicos de movimento de trabalho e as políticas públicas levam à redução da desigualdade de renda entre as regiões.

Nos anos 1980, a teoria do capital humano de Lucas (1988) propôs que a atividade escolhida pela pessoa para alocar seu tempo afeta a produtividade no período futuro. Assim, políticas capazes de aumentar o tempo despendido com qualificação podem gerar aumento constante no crescimento do produto por trabalhador. $\mathrm{O}$ modelo de Lucas leva à conclusão de que um país com baixos níveis de capital humano (qualificação por meio da educação) permanecerá com menor nível de renda per capita do que uma economia com nível educacional mais alto. Essa é a mesma conclusão do modelo de Romer (1994).

Com base nessas teorias, alguns estudiosos acreditam que políticas educacionais focadas no indivíduo são mais eficientes na distribuição de renda do que aquelas com foco no território. Pessôa (1999), por exemplo, argumenta que o aumento no nível educacional das pessoas mais pobres equaliza os salários reais entre as regiões. Isso acontece porque as pessoas tendem a migrar para regiões que pagam maiores salários e, por sua vez, o capital pode migrar para região que oferta mão de obra qualificada mais barata. O resultado final seria, portanto, uma melhor distribuição de renda.

São frequentes trabalhos empíricos que constatam correlação positiva entre educação (anos de escolaridade) e distribuição de renda. No Brasil, o trabalho clássico de Langoni (1973) sugere que o acirramento da desigualdade de renda no país é resultante da escassez relativa de trabalhadores qualificados. Segundo esse autor, o crescimento acelerado da economia brasileira nas últimas décadas levou a um rápido aumento da demanda por trabalhadores qualificados. Entretanto, a oferta deles não se expandiu na mesma intensidade, resultando em um aumento substancial da renda desses trabalhadores. Um trabalho mais recente, de Menezes e Lisboa (2001), aponta que as desigualdades na distribuição da renda no Brasil podem ser explicadas pela desigualdade de educação (anos de escolaridade dos brasileiros). O estudo desses autores sugere que a desigualdade de renda no Brasil seria $60 \%$ menor do que é hoje se todos os trabalhadores tivessem o mesmo acesso à educação.

A ampliação da oferta de trabalhadores qualificados é uma das soluções que vem sendo proposta para resolver o problema da desigualdade brasileira. Tal visão tem sido criticada por alguns estudiosos. Alves (2004), por exemplo, afirma que soluções não devem ser buscadas para o problema da desigualdade na simples ampliação do sistema educacional. As mudanças devem ocorrer por meio de política de reforma do sistema que "venha a modificar as condições de oferta e demanda por educação, de modo a colocá-las em linha com as reais necessidades de recursos da nação" (Alves, 2004, p. 503).

Além de políticas educacionais, outras teorias são formuladas para explicar as diferenças regionais de renda. Ravallion e Jalan (1996) sugerem, além da educação, variáveis geográficas, tais como: instituições políticas e jurídicas, clima, infraestrutura e tecnologia local, as quais podem afetar a produtividade marginal do trabalho e do capital. Tais modelos revelam ainda que gastos na educação dos indivíduos de regiões menos desenvolvidas não são suficientes para elevar a produtividade marginal do trabalho e do capital a ponto de atrair empresas de regiões mais desenvolvidas do país.

Como acima apontado, o conhecimento é um bem público, sendo socialmente indivisível. Assim, o custo marginal de um usuário adicional de conhecimento tende a zero, fazendo com que o estoque de conhecimento acumulado não seja diminuído com o seu uso intensivo, mas, pelo contrário, faz aumentar esse mesmo estoque por um movimento que os e economistas chamam de externalidades positivas (Dasrupta \& David, 1994). Em outros termos, para a teoria econômica, em contraste com outros fatores de produção, não há custo de oportunidade e rendimentos decrescentes com o aumento da educação superior, cuja ampliação e transmissão são um jogo de soma positiva. 


\section{Metodologia}

Os dados utilizados neste trabalho foram obtidos a partir do site da CAPES, que possui um portal na Internet com estatísticas, denominadas GeoCAPES. Esta base disponibiliza vários indicadores da pós-graduação, tais como: distribuição de programas, avaliações atribuídas, docentes e discentes, acesso ao portal de periódicos e distribuição de cursos da Universidade Aberta do Brasil. O período de análise deste estudo se referiu à série histórica de 1998 a 2011, porque esse intervalo abrange a série mais longa de indicadores da pós-graduação disponibilizada pela CAPES (n.d.a), quando foi realizado esse trabalho.

A linha metodológica utilizada é a análise descritiva dos dados, trabalhados e apresentados em gráficos e em tabelas, com o objetivo de comparar os indicadores: programas, docentes e discentes, matriculados e titulados, entre as regiões brasileiras, traçando-se um panorama geral do estrito senso em Administração. As análises descritivas servem para analisar o comportamento de variáveis utilizando-se de dados quantitativos (Contandriopoulos, Champagne, Potvin, Denis, \& Boyle, 1997).

Para assegurar a qualidade dos dados, foram adotados os procedimentos metodológicos expostos a seguir. A primeira etapa da pesquisa consistiu na organização da base de dados GeoCAPES. Realizou-se, assim, um trabalho exaustivo e sistemático, a fim de construir a base e elaborar as tabelas. Para se chegar à organização desejada, foi necessário separar cada indicador, como, por exemplo, a distribuição de programas de pós-graduação, a de discentes e a de docentes, por área do conhecimento (Administração). Em seguida, foi necessário, também, separar cada um dos indicadores por região (Sudeste, Sul, Nordeste, Centro-Oeste ou Norte), por nível (mestrado, mestrado profissional ou doutorado), computando também o corpo docente e o discente, e a avaliação atribuída a cada programa, por categoria administrativa (pública ou privada) da IES. Todas essas informações foram organizadas ano a ano, isto é, desde 1998 até 2011. Para algumas figuras e tabelas, a apresentação de dados considera somente o último ano do triênio, pois a qualificação de programas só ocorre nestas datas.

Uma vez feita a organização dos dados, elaboraram-se as figuras, a fim de mostrar o comportamento dos indicadores investigados ao longo do tempo e, também, realizar uma análise comparativa entre as regiões brasileiras e categorias de IES, entre outras variáveis. A representação de dados por meio de gráficos torna-se uma forma atrativa e expressiva de apresentação, pois facilita a visão do conjunto das informações (Marconi \& Lakatos, 2002).

\section{Análise dos Resultados}

Nesta seção, realizou-se uma análise descritiva dos dados coletados, com o objetivo de se conhecer não só a evolução do ensino da pós-graduação, mas também comparar indicadores, tais como IESs, programas, docentes, discentes matriculados e titulados, entre as regiões brasileiras, obtendo, assim, um panorama geral sobre o tema. As subseções a seguir analisam os principais indicadores desse nível de ensino.

\section{Programas}

A CAPES é responsável pelo credenciamento ${ }^{(5)}$ e pela avaliação trienal dos programas de mestrado e doutorado. Ressalta-se que, para analisar esse indicador, foi necessário separar os programas em cursos de mestrado, doutorado e mestrado profissional, uma vez que, em alguns anos, tais cursos são contabilizados em conjunto.

A Figura 1 mostra a forte evolução, ao longo dos 14 anos, dos programas de pós-graduação por nível de curso (mestrado, doutorado e mestrado profissional). Os cursos de doutorado, em 1998, 
contabilizavam apenas 8 e, em 2011, somam 29, com tendência à alta. O mestrado acadêmico mostra um crescimento forte, mas com certa desaceleração nos últimos cinco anos. Já o mestrado profissional vem apresentando um crescimento mais expressivo quando comparado às demais modalidades. $\mathrm{Ou}$ seja, em 1998, existiam só três programas, enquanto que, em 2011, 32 cursos já tinham sido implantados.

Portanto, em 2011, a pós-graduação reunia um total de 118 programas. Tanto nos cursos de doutorado quanto nos de mestrado, esses números vêm aumentando rapidamente ao longo dos triênios de avaliação. Tal expansão pode ser explicada não só pelo aumento da oferta de cursos de pósgraduação derivada de estímulos orçamentários ${ }^{(6)}$ do governo destinados a essa modalidade de ensino, mas sobretudo pelo aumento da demanda da sociedade por maior nível de escolarização, que se tornou uma exigência para o ingresso no mercado de trabalho. Essa demanda foi respondida também pelas IESs privadas, como será visto à frente.

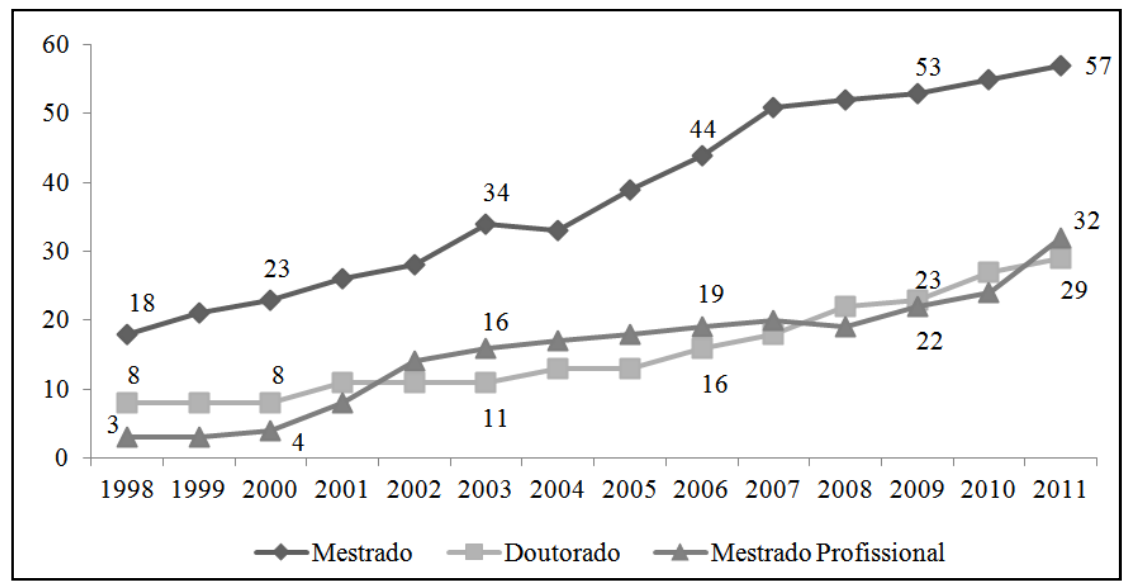

Figura 1. Evolução do Número de Programas Estrito Senso em Administração por Nível de Curso Brasil 1998-2011.

Fonte: elaborada a partir da base de dados GeoCAPES (Coordenação de Aperfeiçoamento de Pessoal de Nível Superior. (n.d.a). GeoCAPES dados estatísticos. Recuperado de http://geocapes.capes.gov.br/geocapesds/\#).

Os dados apresentados na Figura 2 mostram de outra forma o que se expôs acima, ou seja, a taxa de expansão da oferta de todos os níveis de curso: mestrado, doutorado e mestrado profissional. As taxas são muito expressivas para os 14 anos analisados. As taxas médias anualizadas são as seguintes, para a mesma ordem dos cursos: $15,5 \%, 18,7 \%$ e $69 \%$. Tal crescimento dos mestrados profissionais é impressionante, fazendo-se registrar que a curva da Figura 1 mostra um período de relativa estabilidade entre 2002 e 2007 devido, talvez, às inseguranças que ainda recaíam sobre a avaliação desse tipo de curso pela CAPES, o que merece ser investigado.

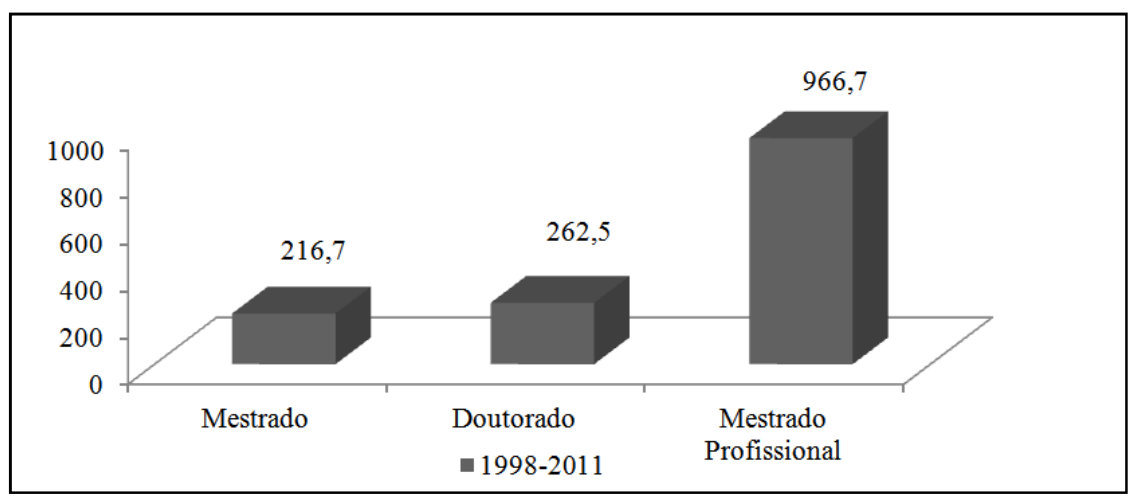

Figura 2. Taxa de Crescimento dos Programas Estrito Senso em Administração por Nível de Curso entre 1998 e 2011.

Fonte: elaborada a partir da base de dados GeoCAPES (Coordenação de Aperfeiçoamento de Pessoal de Nível Superior. (n.d.a). GeoCAPES dados estatísticos. Recuperado de http://geocapes.capes.gov.br/geocapesds/\#). 
A Figura 3 mostra a participação relativa de cada nível no total de programas, agora mostrando somente os anos finais da avaliação trienal (além de 2011, penúltimo ano do atual triênio). Como se pode observar, a participação relativa do mestrado acadêmico caiu entre 1998 e 2011 . A proporção dos cursos de doutorado manteve-se constante. Por outro lado, o mestrado profissional vem incrementando sua participação de forma significativa.

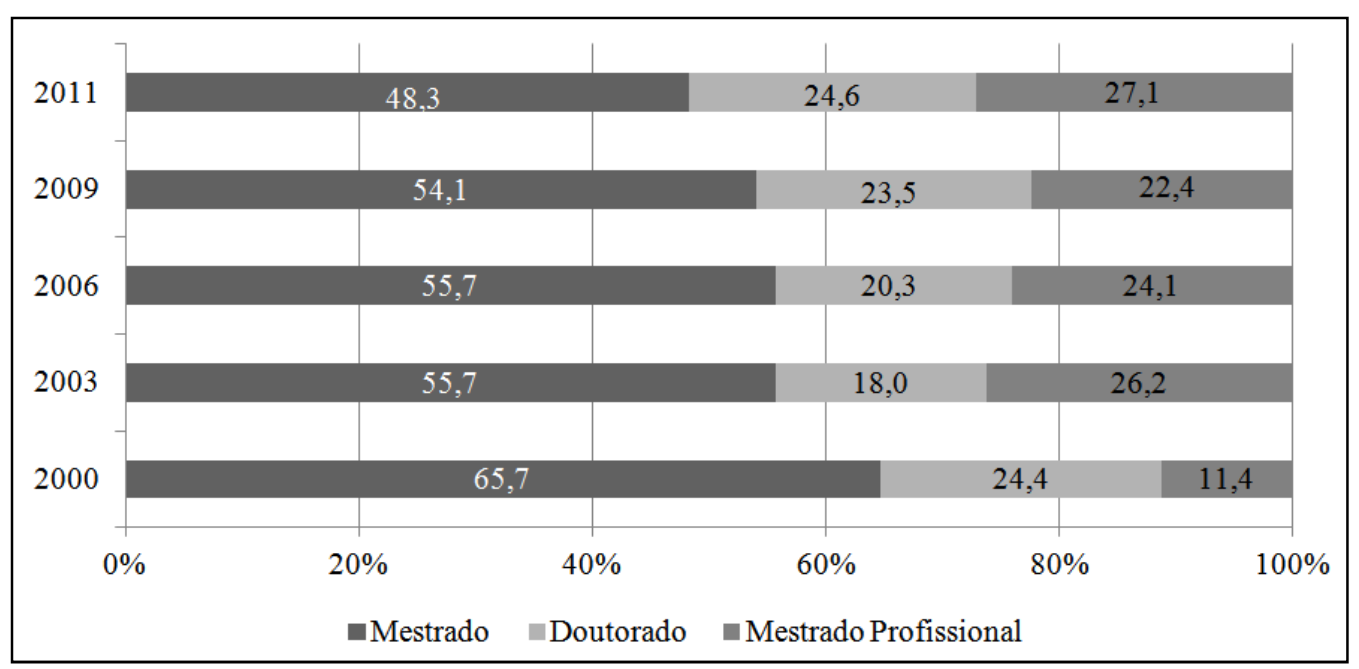

Figura 3. Participação Relativa dos Níveis de Pós-graduação Estrito Senso em Administração - Brasil 2000, 2003, 2006, 2009 e 2011.

Fonte: elaborada a partir da base de dados GeoCAPES (Coordenação de Aperfeiçoamento de Pessoal de Nível Superior. (n.d.a). GeoCAPES dados estatísticos. Recuperado de http://geocapes.capes.gov.br/geocapesds/\#).

As comparações regionais são essenciais para analisar a realidade do país. Os dados comparativos entre as regiões brasileiras na Figura 4 apontam que, em 2011, dentre um total de 118 cursos de pós-graduação, $51,7 \%$ estavam na região Sudeste, $25,4 \%$ no Sul, $17,8 \%$ no Nordeste, e somente 3,4\% no Centro-Oeste e 1,7\% no Norte. Portanto, as desigualdades regionais são marcantes no que diz respeito à distribuição geográfica do número de programas de pós-graduação. Isso influencia diretamente na produção científica e tecnológica nacional e nas perspectivas do crescimento regional, pois quanto mais cursos de pós-graduação, desde que implantados com qualidade, maior será a produção de conhecimento e seu efeito no desenvolvimento regional.

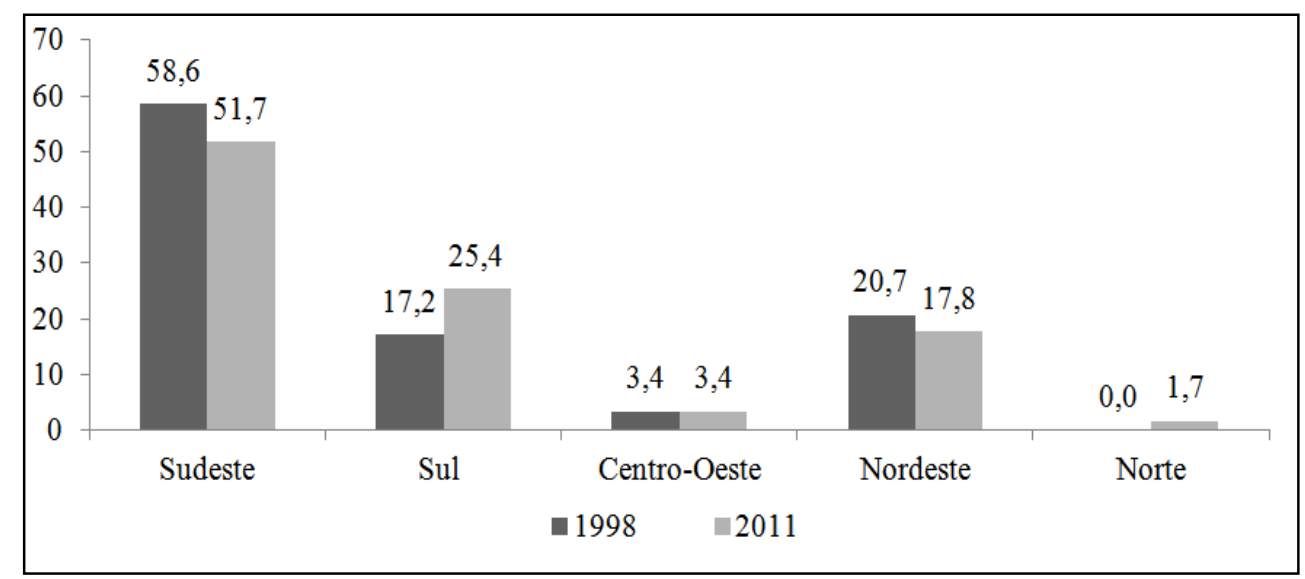

Figura 4. Distribuição Percentual do Número de Programas de Pós-graduação Estrito Senso em Administração, Segundo as Regiões - Brasil 1998 e 2011.

Fonte: elaborada a partir da base de dados GeoCAPES (Coordenação de Aperfeiçoamento de Pessoal de Nível Superior. (n.d.a). GeoCAPES dados estatísticos. Recuperado de http://geocapes.capes.gov.br/geocapesds/\#).

Embora a região Sudeste tenha perdido pequena margem de concentração, o Sul aumentou significativamente. As regiões mais pobres, no seu conjunto, perderam participação relativa, 
exatamente no momento em que deveriam ter, no mínimo, acompanhado o crescimento médio verificado no país. A região Norte apresentou aumento da taxa em relação a 1998, passando de $0 \%$ para $1,7 \%$, sendo essa informação positiva, mas aquém do desejado, dada a extensão da região em termos espaciais e demográficos. A queda da participação relativa da região Nordeste necessita de uma explanação em profundidade devido a sua importância na economia e na política nacional. A rigor, havia uma expectativa do governo de que a distribuição desigual entre as regiões fosse corrigida ao longo do tempo. Isso porque as agências de fomento federais, tais como CAPES, CNPq e Finep ${ }^{(7)}$, vêm incentivando a formação de parcerias entre programas de regiões distintas a fim de promover a desconcentração do sistema nacional de pós-graduação. Ademais, visando superar as assimetrias regionais, desde 2008, a CAPES realiza chamadas públicas para o recebimento de projetos de implantação de redes de cooperação acadêmica na área de Administração, visando à formação de pessoal nas modalidades de Mestrados e Doutorados Interinstitucionais (MINTER e DINTER) (CAPES, n.d.b).

A Figura 5 mostra a evolução em números absolutos dos programas de pós-graduação segundo a categoria administrativa da IES (pública ou privada). A Tabela 1 apresenta a distribuição percentual desses números para cada região. Observa-se que a quantidade de cursos ofertados pela esfera privada ganhou importância nos últimos doze anos. Em 1998, eram 10 programas no Brasil, equivalente a $34,5 \%$; em 2009, aumentaram para 54, equivalentes a 55,1\% (Figura 5 e Tabela 1).

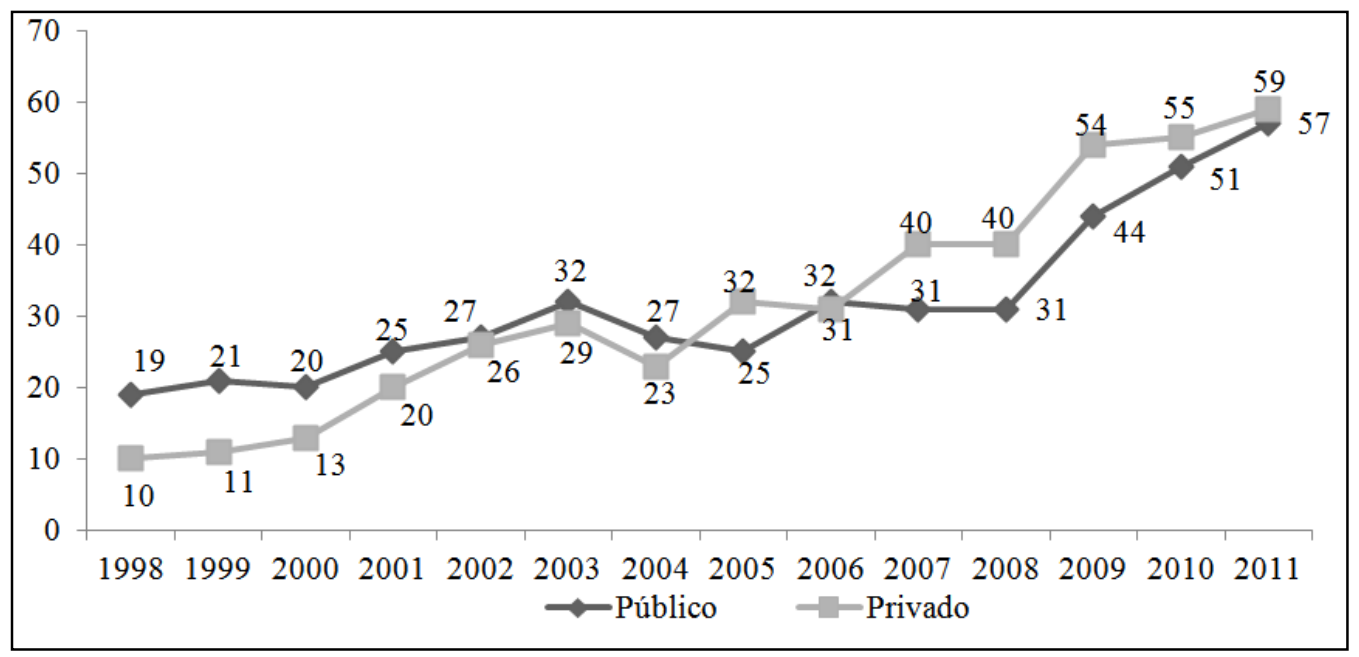

Figura 5. Evolução dos Programas Estrito Senso em Administração por Categoria Administrativa da IES - Brasil 1998-2011.

Fonte: elaborada a partir da base de dados GeoCAPES (Coordenação de Aperfeiçoamento de Pessoal de Nível Superior. (n.d.a). GeoCAPES dados estatísticos. Recuperado de http://geocapes.capes.gov.br/geocapesds/\#).

A ampliação dos cursos públicos não se deu de forma tão sistemática quanto aos particulares, o que pode ser visto na Tabela 1. Há uma relativa estagnação no período de 2003 a 2008, com uma recuperação posterior. Enquanto entre 1998 e 2011, a taxa de expansão do setor público correspondeu a um aumento de $190,0 \%$, a taxa dos cursos privados foi de 440,0\%. Convém chamar a atenção para o fato de que essas estatísticas são fortemente influenciadas pela região Sudeste, que possui a grande maioria dos programas na esfera privada, conforme será visto a seguir. O Centro-Oeste mostra um crescimento grande, porém a partir de uma base muito pequena. 
Tabela 1

Distribuição Percentual dos Programas de Pós-graduação Estrito Senso em Administração ao Final do Triênio de Avaliação (2000, 2003, 2006, 2009, 2011), por Regiões, segundo a Categoria Administrativa da IES

\begin{tabular}{|c|c|c|c|c|c|c|c|c|c|c|c|}
\hline \multirow[b]{2}{*}{ Categoria } & \multicolumn{2}{|c|}{2000} & \multicolumn{2}{|c|}{2003} & \multicolumn{2}{|c|}{2006} & \multicolumn{2}{|c|}{2009} & \multicolumn{2}{|c|}{2011} & \multirow{2}{*}{$\begin{array}{c}2000 / 2011 \\
\Delta \%\end{array}$} \\
\hline & Total & $\%$ & Total & $\%$ & Total & $\%$ & Total & $\%$ & Total & $\%$ & \\
\hline \multicolumn{12}{|l|}{ Brasil } \\
\hline Pública & 20 & 62,5 & 32 & 52,5 & 31 & 49,2 & 44 & 45,9 & 58 & 49,1 & 190,0 \\
\hline Privada & 12 & 37,5 & 29 & 47,5 & 32 & 50,8 & 54 & 54,1 & 60 & 50,9 & 400,0 \\
\hline \multicolumn{12}{|l|}{ Sudeste } \\
\hline Pública & 8 & 42,1 & 14 & 37,8 & 11 & 34,4 & 15 & 28,8 & 21 & 43,7 & 162,5 \\
\hline Privada & 11 & 57,9 & 23 & 62,2 & 21 & 75,6 & 37 & 71,2 & 40 & 56,3 & 263,6 \\
\hline \multicolumn{12}{|l|}{ Sul } \\
\hline Pública & 6 & 100 & 8 & 66,7 & 8 & 53,3 & 11 & 52,2 & 15 & 50,0 & 150,0 \\
\hline Privada & - & - & 4 & 33,3 & 7 & 46,7 & 12 & 47,8 & 15 & 50,0 & - \\
\hline \multicolumn{12}{|l|}{ Centro-Oeste } \\
\hline Pública & 1 & 100 & 1 & 100 & 2 & 100 & 4 & 80,0 & 4 & 100 & 300,0 \\
\hline Privada & - & - & - & - & - & - & 1 & 20,0 & - & - & - \\
\hline \multicolumn{12}{|l|}{ Nordeste } \\
\hline Pública & 5 & 83,3 & 9 & 81,8 & 9 & 69,2 & 13 & 76,5 & 17 & 81,0 & 240,0 \\
\hline Privada & 1 & 16,7 & 2 & 18,2 & 4 & 30,8 & 4 & 23,5 & 4 & 19,1 & 300 \\
\hline \multicolumn{12}{|l|}{ Norte } \\
\hline Pública & - & - & - & - & 1 & 100 & 1 & 100 & 1 & 50,0 & - \\
\hline Privada & - & - & - & - & - & - & - & - & 1 & 50,0 & - \\
\hline
\end{tabular}

Nota. Fonte: elaborada a partir da base de dados GeoCAPES (Coordenação de Aperfeiçoamento de Pessoal de Nível Superior. (n.d.a). GeoCAPES dados estatísticos. Recuperado de http://geocapes.capes.gov.br/geocapesds/\#).

A Tabela 2 mostra outras dimensões da dinâmica do setor, apontando para a característica administrativa dos cursos (públicos e privados) e a avaliação trienal de qualidade da CAPES (escala de 3 a 7). Em termos agregados, em 1998, havia uma clara dianteira de número de cursos na esfera pública, invertendo esta situação em 2011, com um número muito maior de cursos. Essa tendência está de acordo com o processo de expansão e privatização do sistema de ensino brasileiro, especialmente nas regiões mais desenvolvidas do país. A região Sudeste sempre teve uma maior participação do setor privado, mesmo que em 1998 esta fosse modesta (11 particulares e 8 públicos). Em 2011, há praticamente o dobro de cursos privados nesta região (41 contra 20). No Sul, o mesmo fenômeno é verificado, porém em menor volume. O Centro-Oeste e o Nordeste dependem fundamentalmente do esforço do setor público para o seu crescimento em termos quantitativos.

Sobre a ótica qualitativa, houve uma melhora significativa dos cursos. No Brasil, em 1998, de um total de 32 cursos, não existiam conceitos 6 e 7. Em 2006, aparecem os primeiros conceitos 6 e somente no último triênio aparecem dois conceitos 7. Em termos do setor privado, em 2000, havia 2 cursos com conceitos 5, o máximo atingido; 2011 apresenta 18 destes cursos (conceitos 5 e 6), superando os cursos privados, mas não atingindo a excelência do setor público com dois cursos com conceito 7. No geral, é relevante o crescimento qualitativo por via do aumento dos cursos com conceitos 4,5 e 6 em todos os programas, mas com destaque para o setor privado e para a região 
Sudeste, que puxou a estatística de forma positiva. No entanto, excetuando o Sudeste, a predominância do conceito $3 \mathrm{em}$ todas as regiões indica que um longo caminho há que ser percorrido para ambas as categorias de IESs, particularmente no Nordeste.

Tabela 2

Distribuição da Pós-graduação Estrito Senso em Administração ao Final do Triênio de Avaliação (2000, 2003, 2006, 2009, 2011) por Regiões, por Conceito CAPES, segundo Categoria Administrativa IES - Brasil

\begin{tabular}{|c|c|c|c|c|c|c|c|c|c|c|}
\hline & \multicolumn{2}{|c|}{2000} & \multicolumn{2}{|c|}{2003} & \multicolumn{2}{|c|}{2006} & \multicolumn{2}{|c|}{2009} & \multicolumn{2}{|c|}{2011} \\
\hline & Pub & Priv & Pub & Priv & Pub & Priv & Pub & Priv & Pub & Priv \\
\hline \multicolumn{11}{|l|}{ Brasil } \\
\hline conceito 3 & 6 & 5 & 15 & 17 & 18 & 17 & 16 & 21 & 26 & 20 \\
\hline conceito 4 & 6 & 5 & 4 & 14 & 5 & 9 & 10 & 19 & 18 & 20 \\
\hline conceito 5 & 8 & 2 & 8 & 3 & 6 & 5 & 14 & 12 & 8 & 18 \\
\hline conceito 6 & 0 & 0 & - & - & 2 & 1 & 4 & 2 & 4 & 2 \\
\hline conceito 7 & - & - & - & - & - & - & - & - & 2 & - \\
\hline Total & 20 & 12 & 27 & 34 & 31 & 32 & 44 & 54 & 58 & 60 \\
\hline \multicolumn{11}{|l|}{ Sudeste } \\
\hline conceito 3 & 1 & 4 & 6 & 11 & 7 & 10 & 6 & 14 & 8 & 13 \\
\hline conceito 4 & 3 & 5 & 4 & 12 & 1 & 5 & 1 & 11 & 7 & 12 \\
\hline conceito 5 & 4 & 2 & 4 & & 2 & 5 & 6 & 10 & 2 & 13 \\
\hline conceito 6 & - & - & - & - & 1 & 1 & 2 & 2 & 2 & 2 \\
\hline conceito 7 & - & - & - & - & - & - & - & - & 1 & - \\
\hline Total & 8 & 11 & 14 & 23 & 11 & 21 & 15 & 37 & 20 & 40 \\
\hline \multicolumn{11}{|l|}{ Sul } \\
\hline conceito 3 & 3 & - & 4 & 4 & 5 & 3 & 2 & 3 & 6 & 4 \\
\hline conceito 4 & 1 & - & & - & 1 & 4 & 4 & 7 & 7 & 6 \\
\hline conceito 5 & 2 & - & 4 & - & 1 & - & 3 & 2 & - & 5 \\
\hline conceito 6 & & - & - & - & 1 & - & 2 & - & 2 & - \\
\hline conceito 7 & & - & - & - & - & - & - & - & 1 & - \\
\hline Total & 6 & 0 & 8 & 4 & 8 & 7 & 11 & 12 & 16 & 15 \\
\hline
\end{tabular}

Centro-Oeste

\begin{tabular}{rrrrrrrrrrr} 
conceito 3 & 1 & - & 1 & - & - & - & 1 & 1 & 2 & - \\
conceito 4 & - & - & - & - & 2 & - & 3 & - & - & - \\
conceito 5 & - & - & - & - & - & - & - & - & 2 & - \\
conceito 6 & - & - & - & - & - & - & - & - & - & - \\
conceito 7 & - & - & - & - & - & - & - & - & - & - \\
\cline { 2 - 10 } Total & 1 & 0 & 1 & 0 & 2 & 0 & 4 & 1 & 4 & 0 \\
\hline
\end{tabular}


Tabela 2 (continuação)

\begin{tabular}{|c|c|c|c|c|c|c|c|c|c|c|}
\hline & \multicolumn{2}{|c|}{2000} & \multicolumn{2}{|c|}{2003} & \multicolumn{2}{|c|}{2006} & \multicolumn{2}{|c|}{2009} & \multicolumn{2}{|c|}{2011} \\
\hline & Pub & Priv & Pub & Priv & Pub & Priv & Pub & Priv & Pub & Priv \\
\hline \multicolumn{11}{|l|}{ Nordeste } \\
\hline conceito 3 & 1 & 1 & 4 & 2 & 5 & 4 & 6 & 3 & 9 & 2 \\
\hline conceito 4 & 2 & - & - & 2 & 1 & - & 2 & 1 & 4 & 2 \\
\hline conceito 5 & 2 & - & - & 3 & 3 & - & 5 & - & 4 & - \\
\hline conceito 6 & - & - & - & - & - & - & - & - & - & - \\
\hline conceito 7 & - & - & - & - & - & - & - & - & - & - \\
\hline Total & 5 & 1 & 4 & 7 & 9 & 4 & 13 & 4 & 17 & 4 \\
\hline \multicolumn{11}{|l|}{ Norte } \\
\hline conceito 3 & - & - & - & - & 1 & - & 1 & - & 1 & 1 \\
\hline conceito 4 & - & - & - & - & - & - & - & - & - & - \\
\hline conceito 5 & - & - & - & - & - & - & - & - & - & - \\
\hline conceito 6 & - & - & - & - & - & - & - & - & - & - \\
\hline conceito 7 & - & - & - & - & - & - & - & - & - & - \\
\hline Total & 0 & 0 & 0 & 0 & 1 & 0 & 1 & 0 & 1 & 1 \\
\hline
\end{tabular}

Nota. Fonte: elaborada a partir da base de dados GeoCAPES (Coordenação de Aperfeiçoamento de Pessoal de Nível Superior. (n.d.a). GeoCAPES dados estatísticos. Recuperado de http://geocapes.capes.gov.br/geocapesds/\#).

\section{Discentes}

Um maior desafio do sistema de ensino da pós-graduação é a formação de recursos humanos altamente capacitados por via dos cursos credenciados. Um estímulo aos discentes é o volume de recursos destinados a bolsas de estudos do CNPq e da CAPES, que saltou de R\$ 813 milhões em 2000, para cerca de R\$ 2.973 milhões em 2011, o que significa que, neste ano, houve um total de aporte suficiente para cerca de 67 mil alunos, entre mestres e doutores (CAPES, n.d.a). No entanto, para a área de ciências sociais aplicadas, esse percentual é relativamente pequeno, representando, em 2010, cerca de 5000, dos quais somente 23\% para a área de Administração, ou seja, 1150.

\section{Matriculados}

A quantidade de matrículas na pós-graduação saltou de 2686 em 2000 para 5391 em 2011, conforme a Tabela 3, praticamente dobrando os alunos matriculados. Os dados percentuais são desiguais, reforçando o problema das assimetrias regionais já apontado anteriormente. O que chama a atenção é a queda relativa sistemática nas matrículas no Nordeste (no Centro-Oeste, que inclui Brasília, houve queda abrupta, devendo esse fato ser estudado à parte). O crescimento das matrículas no Sudeste e no Sul indica que a demanda nessas regiões esteve muito aquecida, contribuindo para o aumento do número de cursos implantados. 
Tabela 3

Percentuais de Matrículas da Pós-graduação Estrito Senso em Administração ao Final dos Triênios de Avaliação (2000, 2003, 2006, 2009, 2011) por Região no Brasil

\begin{tabular}{cccccccc}
\hline \multirow{2}{*}{ Ano } & Sudeste & Sul & Nordeste & $\begin{array}{c}\text { Centro- } \\
\text { Oeste }\end{array}$ & Norte & Total & $(\%)$ \\
\cline { 2 - 8 } & 59,9 & 11,1 & 15,6 & 13,4 & 0 & 2.686 & 100,0 \\
2000 & 67,2 & 18,6 & 13,5 & 0,8 & 0 & 3.261 & 100,0 \\
2003 & 64,6 & 17,3 & 16,1 & 1,4 & 0,6 & 3.978 & 100,0 \\
2006 & 58,8 & 21,4 & 16,1 & 2,9 & 0,8 & 4.661 & 100,0 \\
2011 & 64,3 & 18,8 & 13,2 & 2,4 & 1,3 & 5.391 & 100,0 \\
\hline
\end{tabular}

Nota. Fonte: elaborada a partir da base de dados GeoCAPES (Coordenação de Aperfeiçoamento de Pessoal de Nível Superior. (n.d.a). GeoCAPES dados estatísticos. Recuperado de http://geocapes.capes.gov.br/geocapesds/\#).

As taxas de crescimento desse indicador foram bastante significativas para todas as modalidades de curso, como mostra a Figura 6. Os dados do número de matrículas, no entanto, revelam três movimentos distintos. No doutorado, o aumento é sistemático, praticamente triplicando o número de matrículas, com viés de expansão. O mestrado acadêmico mostra certa estagnação nos últimos cinco anos, sem mostras de uma recuperação, provavelmente devido à concorrência dos mestrados profissionais, estes com um movimento de rápido crescimento até 2005, queda entre 2006 e 2007 e, depois, uma rápida recuperação, refletindo ainda o debate em torno de sua efetiva regulamentação. Mas é significativo apontar que eram 179 alunos matriculados nesse nível de ensino em 1998, enquanto que, em 2011, já chegavam a 1.525. Nesse ritmo, os mestrados profissionais irão superar o volume de matrículas da modalidade acadêmica em poucos anos.

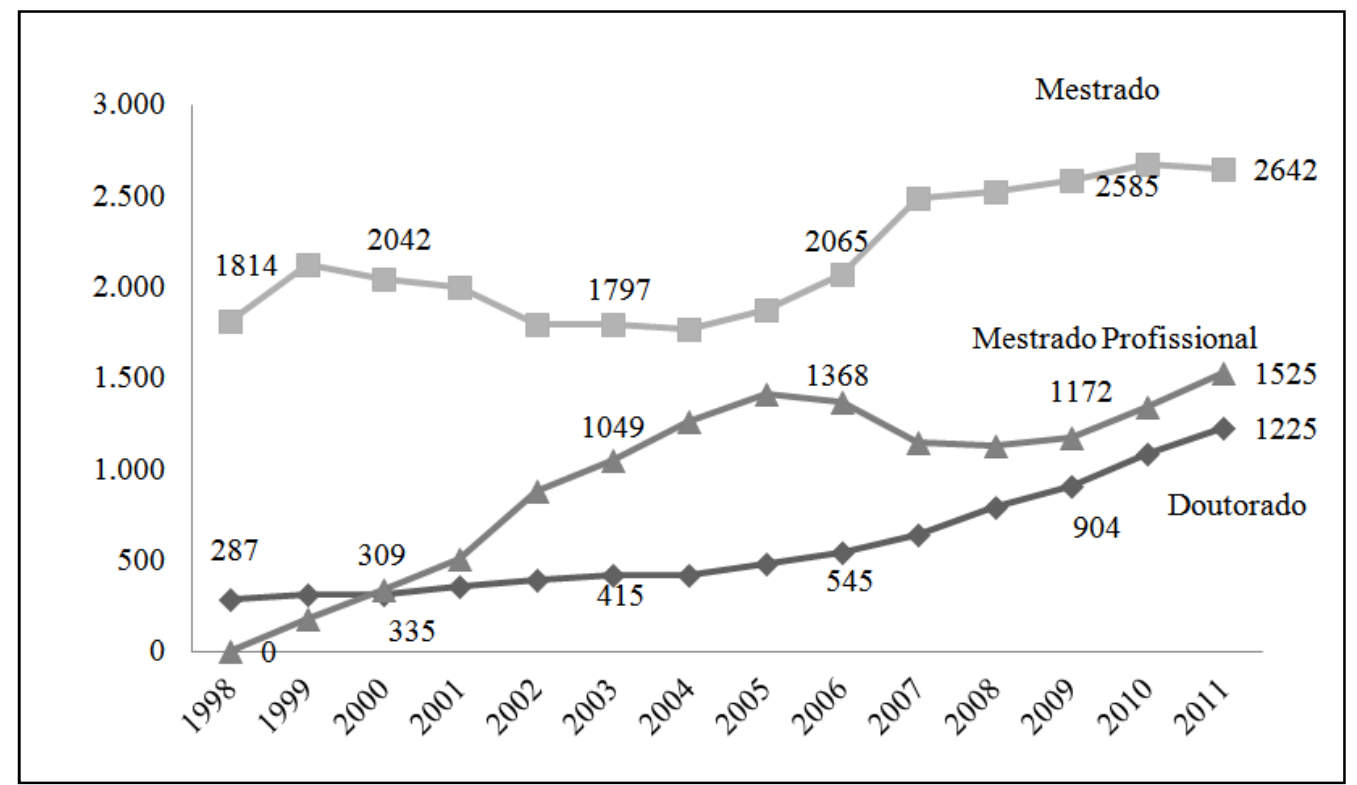

Figura 6. Evolução de Matriculas por Modalidade de Curso.

Fonte: elaborada a partir da base de dados GeoCAPES (Coordenação de Aperfeiçoamento de Pessoal de Nível Superior. (n.d.a). GeoCAPES dados estatísticos. Recuperado de http://geocapes.capes.gov.br/geocapesds/\#). 


\section{Titulados}

Entre 2000 e 2011, o número de titulados no doutorado aumentou em 243,3\% e o de mestrado em aproximadamente $59,1 \% \%$, conforme dados da Tabela 4 . No mestrado profissional, esse indicador cresceu $621,6 \%$. Isso já era previsto e está fortemente associado à expansão sistemática da quantidade de programas e matrículas nesse nível de ensino. No que diz respeito ao total, 1.799 discentes obtiveram titulação em 2011, contra 840 no início do período. Isso corresponde a um aumento de $214,1 \%$ em relação a 2000.

Tabela 4

Número de Titulados da Pós-graduação Estrito Senso em Administração ao Final dos Triênios de Avaliação (2000, 2003, 2006, 2009, 2011) por Modalidade de Curso - Brasil

\begin{tabular}{lcccccc}
\hline Curso & $\mathbf{2 0 0 0}$ & $\mathbf{2 0 0 3}$ & $\mathbf{2 0 0 6}$ & $\mathbf{2 0 0 9}$ & $\mathbf{2 0 1 1}$ & $\mathbf{2 0 0 0 / 2 0 1 1} \Delta \boldsymbol{\%}$ \\
\hline Doutor & 60 & 76 & 106 & 167 & 206 & 243,3 \\
Mestre & 706 & 829 & 869 & 1.099 & 1.123 & 59,1 \\
Mestrado Profissional & 74 & 410 & 587 & 454 & 470 & 621,6 \\
\hline Total & $\mathbf{8 4 0}$ & $\mathbf{1 . 3 1 5}$ & $\mathbf{1 . 5 6 2}$ & $\mathbf{1 . 7 2 0}$ & $\mathbf{1 . 7 9 9}$ & $\mathbf{2 1 4 , 1 \%}$
\end{tabular}

Nota. Fonte: elaborada a partir da base de dados GeoCAPES (Coordenação de Aperfeiçoamento de Pessoal de Nível Superior. (n.d.a). GeoCAPES dados estatísticos. Recuperado de http://geocapes.capes.gov.br/geocapesds/\#).

A Tabela 5 mostra a distribuição dos titulados com relação à categoria administrativa, para o final do período. Nota-se que a maioria dos doutores obteve sua titulação em instituições públicas (54,9\% contra 45,1\%, em 2011). No entanto, tanto para os mestrados acadêmicos como profissionais, o setor privado tem ampla maioria na titulação, atingindo, nestes últimos, a parcela de $76,2 \%$. Vale ressaltar que a qualidade do programa é fortemente influenciada pela presença de um curso de doutorado, mas o seu efeito sobre o volume total de matrículas e titulação ainda carece de uma análise mais aprofundada.

Tabela 5

Distribuição Percentual dos Titulados da Pós-graduação Estrito Senso em Administração por Modalidade de Curso, Segundo a Categoria Administrativa da IES - Brasil 2011

\begin{tabular}{lcccccc}
\hline & Público & \multicolumn{5}{c}{ Privado } \\
\cline { 2 - 7 } & Total & $(\boldsymbol{\%})$ & Total & $\mathbf{( \% )}$ & Total & $(\boldsymbol{\%})$ \\
\hline Doutor & 113 & 54,9 & 93 & 45,1 & 206 & 100 \\
Mestre & 541 & 48,2 & 582 & 51,8 & 1223 & 100 \\
Mestre Profissional & 112 & 23,8 & 358 & 76,2 & 470 & 100 \\
\hline
\end{tabular}

Nota. Fonte: elaborada a partir da base de dados GeoCAPES (Coordenação de Aperfeiçoamento de Pessoal de Nível Superior. (n.d.a). GeoCAPES dados estatísticos. Recuperado de http://geocapes.capes.gov.br/geocapesds/\#).

Quanto aos dados regionais, em 2011, os indicadores de titulação acompanham de perto o volume de programas e de matrículas, não merecendo, no momento, um aprofundamento da análise, muito embora esta avaliação deva ser feita em estudos subsequentes, pois as assimetrias regionais estão também presentes na desigual distribuição de titulados. 


\section{Docentes}

De acordo com a Figura 7, o corpo docente da área cresceu sistematicamente. Passou de 455, em 1998, para 1.656, em 2011, compreendendo pessoal de dedicação integral, colaboradores (parcial) e visitantes (temporário). Isso corresponde a um crescimento de $274,7 \%$ no período. O crescimento dos docentes nas IESs privadas é superior no período como um todo, embora atualmente não existam tendências visíveis com base nos dados existentes. Claramente há uma recuperação do volume de docentes na esfera pública, mas nenhuma indicação é possível ser feita sobre a sua constância no futuro. Desses totais, que se equilibram, há cerca de $20 \%$ de docentes colaboradores, o que segue a norma da CAPES, e um percentual irrisório de visitantes (CAPES, n.d.a).

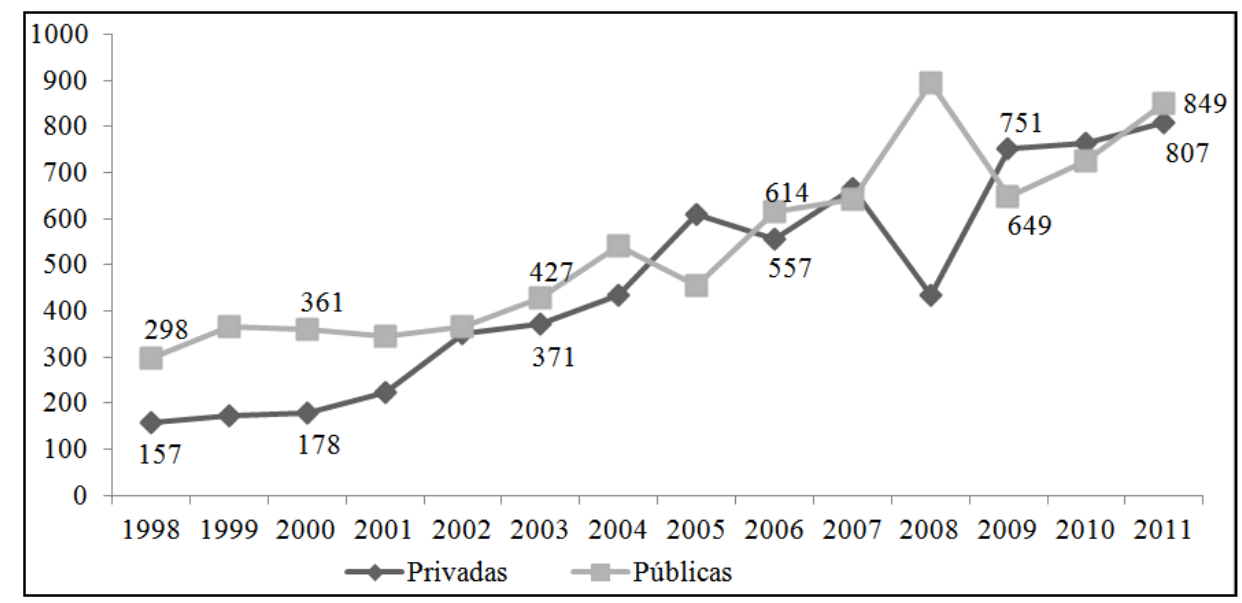

Figura 7. Evolução do Número de Docentes de Pós-graduação Estrito Senso em Administração Segundo Categoria Administrativa.

Fonte: elaborada a partir da base de dados GeoCAPES (Coordenação de Aperfeiçoamento de Pessoal de Nível Superior. (n.d.a). GeoCAPES dados estatísticos. Recuperado de http://geocapes.capes.gov.br/geocapesds/\#).

Outro aspecto relevante refere-se à distribuição geográfica dos docentes. Os dados da Figura 8 indicam que as diferenças regionais são significativas, isto é, em 2011, o Sudeste concentrou mais da metade dos docentes da pós-graduação, seguidos do Sul e Nordeste. Nesta região, há que se observar que, embora o número de programas tenha diminuído, o de docentes aumentou, o que significa maior número de professores por programa na região, o que não ocorreu em outras. Por outro lado, em 2011, nas regiões Centro-Oeste e Norte, observa-se baixa concentração de docentes, reforçando a situação de assimetria nos indicadores para a área sob a ótica regional.

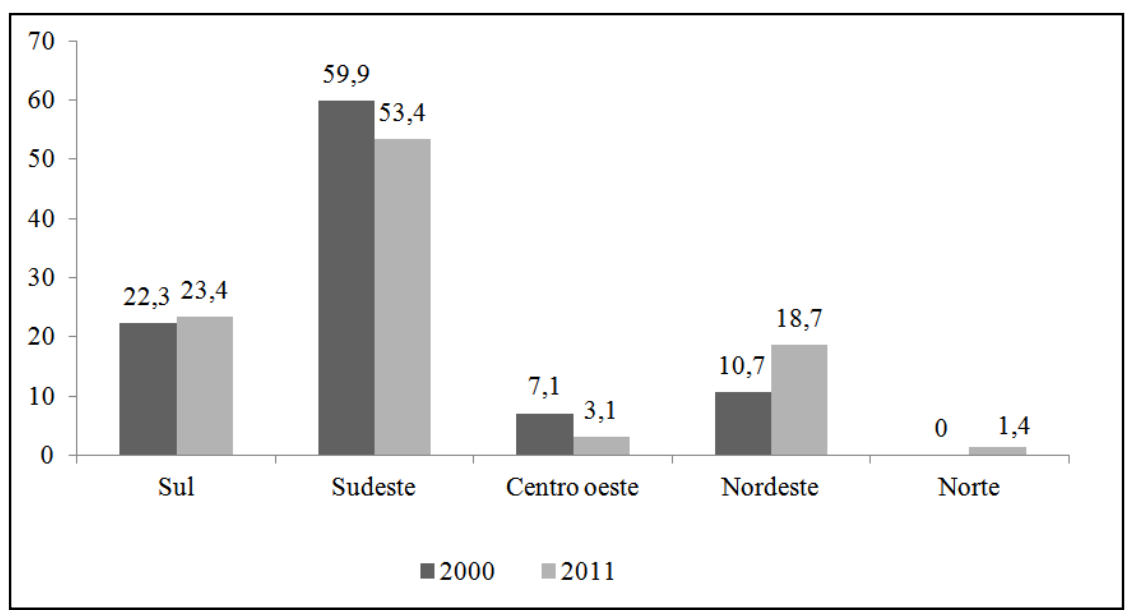

Figura 8. Distribuição Percentual do Número de Docentes de Pós-graduação Estrito Senso em Administração por Região - Brasil 2000 e 2011.

Fonte: elaborada a partir da base de dados GeoCAPES (Coordenação de Aperfeiçoamento de Pessoal de Nível Superior. (n.d.a). GeoCAPES dados estatísticos. Recuperado de http://geocapes.capes.gov.br/geocapesds/\#). 


\section{Considerações Finais}

Este trabalho analisou indicadores básicos do ensino da pós-graduação estrito senso em Administração no Brasil, realizando também uma análise comparativa entre as regiões do país. Tais indicadores apresentaram uma evolução positiva no período analisado - 1998 a 2011. De uma maneira geral, houve ampliação significativa da quantidade e da qualidade de cursos, aumento expressivo do número de discentes, matriculados e titulados, e crescimento do corpo docente. Contudo, essa expansão não ocorreu de forma homogênea em todo o país. Portanto, o desequilíbrio regional ainda é uma realidade, como demonstraram os indicadores de regiões menos favorecidas.

A análise descritiva deste trabalho é apresentada em três etapas: programas, discentes matriculados e titulados - e docentes.

Quanto aos resultados sobre o número de programas, observou-se um aumento expressivo desse indicador. Essa expansão foi sistemática para o doutorado, mostrando uma estabilização de programas e matrículas no mestrado acadêmico. Já os mestrados profissionais apresentam uma rápida recuperação após um breve período de queda nos programas e matrículas. Houve em todas as modalidades um ganho significativo de qualidade, o que pode colocar a área em outro patamar num futuro próximo, particularmente com o aumento do número de programas com notas de padrão internacional (conceitos 6 e 7). No entanto, a distribuição dos cursos entre as regiões brasileiras é extremamente desigual, o que pode comprometer os objetivos de uma área que possa acompanhar o desenvolvimento regional, o que não vem ocorrendo.

Os resultados mostraram ainda que o sistema privado é hoje o principal responsável pelo crescimento da pós-graduação, uma vez que grande parte dos cursos particulares está concentrada na região Sudeste, que representa mais de $50 \%$ dos programas de pós-graduação estrito senso em Administração no país.

A análise do número de matrículas revela que houve crescimento da quantidade de alunos no mestrado, no doutorado e no mestrado profissional, atingindo, em 2011, um total de aproximadamente 5.400. Nos últimos 14 anos, o volume de alunos matriculados no mestrado profissional cresceu expressivos $620 \%$, enquanto no doutorado as matrículas quase triplicaram. Já nos mestrados acadêmicos há uma certa estabilidade, devido à concorrência feita pelos mestrados profissionais.

No que diz respeito ao corpo docente, verificou-se que passou de 455 professores, em 1998, para 1.656, em 2011. Ou seja, a taxa de crescimento foi de $274 \%$ no período. Entretanto, é importante destacar a distribuição geográfica desigual de todos os indicadores aqui investigados, indicando um predomínio das regiões mais desenvolvidas do país. Esse predomínio também se estende para a qualidade dos cursos, com destaque para as IESs privadas que positivamente afetam este indicador.

Espera-se que esses resultados possam subsidiar o setor público e a sociedade, alertando-os para a importância de ações que atendam as necessidades regionais, considerando a manutenção da qualidade do sistema de ensino, pois não se devem buscar as soluções para o problema da assimetria regional na simples ampliação do sistema (Alves, 2004). Assim, acredita-se que o avanço da pósgraduação depende de medidas que visem ampliar também sua qualidade e desempenho.

Inegável que há muito o que fazer para superar as assimetrias regionais. No entanto, alguns resultados vêm sendo alcançados e refletem o esforço das agências de fomento federais, cujas conquistas devem ser preservadas e aprimoradas, tais como a política de cooperação interinstitucional, com o objetivo de planejar programas estratégicos específicos e capacitar o universo docente em regiões menos favorecidas.

Por fim, não se pode deixar de ressaltar que o foco deste trabalho é a pós-graduação em Administração. Entretanto, é fundamental que sejam realizados outros estudos, em outras dimensões 
dessa questão, e mesmo estudos comparativos com outras áreas científicas. Só assim será possível obter análise mais abrangente voltada para a compreensão da pós-graduação estrito senso no Brasil.

\section{Artigo recebido em 02.12.2011. Aprovado em 13.09.2012.}

\section{Notas}

${ }^{1}$ Os cursos de pós-graduação são de dois tipos: o lato senso e o estrito senso. O primeiro grupo refere-se aos cursos de extensão, aperfeiçoamento e especialização. $\mathrm{O}$ estrito senso envolve cursos de mestrado, doutorado e mestrado profissional.

${ }^{2}$ Este trabalho faz parte do Programa de Apoio ao Ensino e à Pesquisa Científica e Tecnológica em Administração (PróAdministração) financiado pela CAPES e liderado pela UNINOVE. O trabalho foi apresentado parcialmente no XIV Semead - Seminários em Administração, 2011, em São Paulo - SP. Na época, os dados de 2010 e 2011 não estavam disponíveis no GeoCAPES.

${ }^{3}$ Neste trabalho, o termo programa é usado como sinônimo de curso, uma vez que na base de dados GeoCAPES utiliza-se tal termo em vez de curso.

${ }^{4}$ Para simplificar, utilizar-se-á, de agora em diante, só o termo pós-graduação para se referir à pós-graduação estrito senso em Administração no Brasil.

${ }^{5} \mathrm{O}$ credenciamento consiste não só na análise documental das propostas apresentadas pelas IES, mas, sobretudo em visitas para verificação in loco da sua fidedignidade.

${ }^{6}$ A CAPES oferece fomento financeiro aos programas de pós-graduação das IES públicas, principalmente federais. Segundo o Instituto de pesquisa Econômica Aplicada. (2010). Políticas sociais: acompanhamento e análise ( $\mathrm{N}^{\mathrm{o}}$ 18, Cap. 5, pp. 115138). Recuperado de http://www.ipea.gov.br/portal/images/stories/PDFs/politicas_sociais/bps_18_cap05.pdf, por meio do programa de Desenvolvimento do Ensino da Pós-Graduação e da Pesquisa Científica, em 2008, foram despendidos mais de R \$ 1 bilhão, com crescimento de 29\% quando comparado ao orçamento executado em 2007.

${ }^{7}$ CNPq e FINEP são siglas que significam, respectivamente, Conselho Nacional de Desenvolvimento Científico e Tecnológico - CNPq e Financiadora de Estudos e Projetos - FINEP.

\section{Referências}

Alves, D. C. O. (2004). Educação, desenvolvimento econômico e distribuição de renda: a experiência brasileira. In D. B. Pinho \& M. A. S. de Vasconcellos (Orgs.), Manual de economia (pp. 500510). São Paulo: Saraiva.

Arrow, K. J. (1962). The economic implications of learding by doing. Review of Economic Studies, 29(3), 153-173. doi: 10.2307/2295952

Campanario, M. A., Maccari, E. A., Silva, M. M., \& Faria, S. G. S. (2009). Desenvolvimento de um curso de mestrado profissional sob a perspectiva da gestão de projetos. Revista Brasileira de Gestão de Negócios, 11(33), 423-442.

Ceretta, C. A., Anjos, L. H. C., \& Siqueira, J. O. (2008). A pós-graduação em ciências do solo no Brasil: evolução e tendências. Revista Brasileira de Pós-Graduação, 5(9), 7-35.

Coen, T., \& Rens, T. (2008). Education, growth, and income inequality. The Review of Economics and Statistics, 90(1), 89-104. doi: 10.1162/rest.90.1.89

Contandriopoulos, A. P., Champagne, F., Potvin, L., Denis, J. L., \& Boyle, P. (1997). Saber preparar uma pesquisa: definição, estrutura e financiamento (2a ed.). São Paulo: Abrasco.

Coordenação de Aperfeiçoamento de Pessoal de Nível Superior. (n.d.). GeoCAPES dados estatísticos. Recuperado de http://geocapes.capes.gov.br/geocapesds/\# 
Coordenação de Aperfeiçoamento de Pessoal de Nível Superior. (n.d.b). Propostas minter/dinter. Recuperado de http://www.capes.gov.br/avaliacao/projetos-dinter-e-minter

Coordenação de Aperfeiçoamento de Pessoal de Nível Superior. (2010). Plano nacional de pós$\begin{array}{llll}\text { graduação } & \text { 2011-2020. } & \text { Recuperado de }\end{array}$ http://www.capes.gov.br/images/stories/download/Livros-PNPG-Volume-I-Mont.pdf

Dasrupta, P., \& David, P. (1994). Toward a new economics of science. Research Policy, 23(5), 487521. doi: 10.1016/0048-7333(94)01002-1

Ferraro, A. R. (2005). A ANPEd, a pós-graduação, a pesquisa e a veiculação da produção intelectual na área da educação. Revista Brasileira de Educação, (30), 47-69. doi: 10.1590/S141324782005000300005

Foray, D. (2004). Economics of knowledge. Cambridge: MIT Press.

Gonçalves, C. E. S., \& Guimarães, B. (2008). Economia sem truques: o mundo a partir das escolhas de cada um. Rio de Janeiro: Elsevier.

Guimarães, T. A., Gomes, A. O., Odelius, C. C., Zancan, C., \& Corradi, A. A. (2009). A rede de programas de pós-graduação em administração no Brasil: análise de relações acadêmicas e atributos de programas. Revista de Administração Contemporânea, 13(4), 564-582. Recuperado de http://www.scielo.br/pdf/rac/v13n4/a04v13n4.pdf. doi: 10.1590/S1415-65552009000400004

Kac, G., Fialho, E., \& Santos, S. M. C. (2006) Panorama atual dos programas de pós-graduação em Nutrição no Brasil. Revista. Nutrição, 19(6), 771-784. doi: 10.1590/S1415-52732006000600012

Kuenzer, A. Z., \& Moraes, M. C. M. (2005). Temas e tramas na pós-graduação em educação. Educação \& Sociedade, 26(93), 1341-1362. doi: 10.1590/S0101-73302005000400015

Langoni, C. G. (1973). Distribuição de renda e desenvolvimento econômico do Brasil. Rio de Janeiro: FGV.

Lucas, R. E., Jr. (1988). On the mechanics of economic development. Journal of Monetary Economics, 22(1), 3-42. doi: 10.1016/0304-3932(88)90168-7

Lyra, T. M. P., \& Haeffner, C. (2008). Análise da pós-graduação em agronomia no Brasil. Revista Brasileira de Pós-Graduação, 5(9), 36-66.

Maccari, E. A., Rodrigues, L. C., Alessio, E. M., \& Quoniam, L. M. (2008). Sistema de avaliação da pós-graduação da CAPES: pesquisa-ação em um programa de pós-graduação em Administração. Revista Brasileira de Pós-Graduação, 5(9), 171-205.

Marconi, M. A., \& Lakatos, E. M. (2002). Técnicas de pesquisa (5a ed.). São Paulo: Atlas.

Martins, C. B. (2000). O ensino superior brasileiro nos anos 90. Revista São Paulo em Perspectiva, 14(1), 41-60. doi: 10.1590/S0102-88392000000100006

Menezes, N. A., Filho, \& Lisboa, M. (2001). Microeconomia e sociedade no Brasil. Rio de Janeiro: Contra-Capa.

Merton, R. K. (1969). Behavior patterns of scientists. American Scientist, 57(1), 1-23.

Moreira, A. F. (2009). A cultura da performatividade e a avaliação da pós-graduação em educação no Brasil. Educação em Revista, 25(3), 23-42. doi: 10.1590/S0102-46982009000300003 
Moretti, S. A., \& Campanario, M. A. (2009). A produção intelectual brasileira em responsabilidade social empresarial - RSE sob a ótica da bibliometria [Edição Especial]. Revista de Administração Contemporânea, 13, 68-86. Recuperado de http://www.scielo.br/pdf/rac/v13nspe/a06v13nspe.pdf. $\quad$ doi: 65552009000500006

Nelson, R., \& Phelps, E. (1966). Investment in humans, technological diffusion and economic growth. American Economic Review, 56(1-2), 69-75. doi: 10.2307/1821269

Pessôa, S. A. (1999). Economia regional, crescimento econômico e desigualdade regional de renda. Rio de Janeiro: FGV.

Pezzi, S., \& Steil, A. V. (2009). Análise do processo de exame de grau na pós graduação stricto sensu. Educação e Pesquisa, 35(1), 33-50. doi: 10.1590/S1517-97022009000100003

Ravallion, M., \& Jalan, J. (1996). Growth divergence due spatial externalities. Economic Letters, 53(2), 227-232. doi: 10.1016/S0165-1765(96)00899-3

Romer, P. M. (1994). The origins of endogenous growth. Journal of Economic Perspectives, 8(1), 322. doi: $10.1257 /$ jep.8.1.3

Santos, C. M. dos (2003). Tradições e contradições da pós-graduação no Brasil. Educação e Sociedade, 24(83), 627-641. doi: 10.1590/S0101-73302003000200016

Silva, M. O. S., \& Carvalho, D. B. B. A. (2007). Pós-graduação e a produção de conhecimento no serviço social brasileiro. Revista Brasileira de Pós-Graduação, 4(8), 192-216.

Solow, R. M. (1956). A contribution to the theory of economic growth. Quarterly Journal of Economics, 70(1), 65-94. doi: 10.2307/1884513

Steiner, J. E. (2005). Qualidade e diversidade institucional na pós-graduação brasileira. Revista Estudos Avançados, 19(54), 341-365. doi: 10.1590/S0103-40142005000200019

Stephan, P. E. (1996). The economics of science. Journal of Economic Literature, 34(3), 1199-1235.

Williamson, J. G. (1965). Regional inequality and the process of national development: a description of the patterns. Economic Development and Cultural Change, 13(4), 1-84. 